\title{
Exposure Assessment of Ambient Sulfur Dioxide Downwind of an Oil Refinery in Curaçao
}

\author{
Erin L. Pulster ${ }^{1}$, Giffe Johnson², Dave Hollander ${ }^{3}$, James McCluskey ${ }^{2}$, Raymond Harbison² \\ ${ }^{1}$ Mote Marine Laboratory, Sarasota, FL, USA \\ ${ }^{2}$ University of South Florida, College of Public Health, Tampa, FL, USA \\ ${ }^{3}$ University of South Florida, College of Marine Science, St. Petersburg, FL, USA \\ Email: gtjohnso@mail.usf.edu
}

How to cite this paper: Pulster, E.L., Johnson, G., Hollander, D., McCluskey, J. and Harbison, R. (2018) Exposure Assessment of Ambient Sulfur Dioxide Downwind of an Oil Refinery in Curaçao. Journal of Environmental Protection, 9, 194-210. https://doi.org/10.4236/jep.2018.93014

Received: December 8, 2017

Accepted: March 20, 2018

Published: March 23, 2018

Copyright $\odot 2018$ by authors and Scientific Research Publishing Inc. This work is licensed under the Creative Commons Attribution International License (CC BY 4.0).

http://creativecommons.org/licenses/by/4.0/

\begin{abstract}
Primary sources of atmospheric sulfur dioxide are anthropogenic activities associated with the burning of fossil fuels and industrial processes that may have associations with various morbidities and mortalities. As such, several regional and global regulatory agencies have recommended ambient air limits to reduce environmental exposures. The objectives of this study were to evaluate ambient levels of sulfur dioxide surrounding an oil refinery on the island of Curaçao. Levels which were then compared to literature values and recommended public health guidelines to determine potential public health risks. Concentrations of sulfur dioxide in Curacao were found to be among the highest globally with an increasing trend over time. While the epidemiological evidence does not conclusively suggest there is a health risk from these levels of exposure, $\mathrm{SO}_{2}$ concentrations greatly exceed regulatory and guidance levels and suggest that further emissions control is warranted. Future recommendations include a more rigorous epidemiological study in Curaçao and expand the air monitoring efforts to include areas upwind of the refinery as well as additional petrochemical emissions.
\end{abstract}

\section{Keywords}

Sulfur Dioxide, Oil Refineries, Public Health, Exposure Assessment, Curaçao

\section{Introduction}

Typical annual average concentrations of ambient sulfur dioxide, as of 2005, have ranged from 9 - $35 \mu \mathrm{g} / \mathrm{m}^{3}$ in North America, 8 - $36 \mu \mathrm{g} / \mathrm{m}^{3}$ in Europe, 40 - 70 $\mu \mathrm{g} / \mathrm{m}^{3}$ in Latin America, $10-100 \mu \mathrm{g} / \mathrm{m}^{3}$ in Africa and $20-200 \mu \mathrm{g} / \mathrm{m}^{3}$ in Asia [1]. 
Atmospheric $\mathrm{SO}_{2}$ is primarily the result of anthropogenic activities associated with the burning of fossil fuels and industrial processes (i.e., oil refineries, coal burning, and biomass combustion) but can also be released naturally from volcanic activities, sea-salt emissions and sulfur gas oxidation [2] [3] [4]. Sulfur dioxide $\left(\mathrm{SO}_{2}\right)$ can be formed from the petroleum refining process and smelting industries, accounting for $15 \%-25 \%$ of the estimated 140 - 350 million tons of sulfur compounds (i.e., sulfur dioxide, sulfuric acids and sulfate) released into the atmosphere annually on a global basis [2] [3] [5].

The Wider Caribbean Region (WCR) includes a number of developing countries for which agriculture, oil and gas exploration in conjunction with processing, provide valuable sources of income. As the WCR is one of the most tourism-dependent regions of the world, factors that affect environmental health and sustainability will have inevitable impacts to the economies and quality of life in many already-needy countries. Approximately 100 oil refineries are located within the WCR, with one of largest and oldest refineries, Isla Refineriá, being located in Willemstad, Curaçao [6]. Communities downwind of Isla Refineriá and the major thoroughfare (Schottegatweg Ring) circling the refinery and the bay have self reported from questionnaires higher than average frequencies of headaches, nausea, chronic lung ailments, asthma and cancer [7]. These self-reported questionnaire results have not been validated. A legacy of human health and environmental issues is the basis of a historical debate and conflict between the public and the local government of Curaçao. However, to our knowledge there has never been an exposure assessment conducted to evaluate ambient atmospheric levels of refinery emissions and their associated public health risks in Curaçao. Sanhueza et al. [8] determined that all areas downwind $(\geq 5 \mathrm{~km})$ of the Isla Refineriá in Curaçao were subject to sulfate contamination exceeding levels which have been previously associated with morbidity ( $\geq 8-12$ $\left.\mu \mathrm{g} / \mathrm{m}^{3}\right)$. In addition, the 2007 yearly average $\mathrm{SO}_{2}$ levels $\left(152 \mu \mathrm{g} / \mathrm{m}^{3}\right)$ measured downwind of the refinery were double the air quality standards for Curaçao $(80$ $\left.\mu \mathrm{g} / \mathrm{m}^{3}\right)$ and exceeded acceptable international guidelines $\left(40-60 \mu \mathrm{g} / \mathrm{m}^{3}\right)$ by almost 2.5 times [9] [10]. In 2009, a court order required the refinery to reduce the excessive $\mathrm{SO}_{2}$ emissions and particulates starting from January 1, 2010.

Sulfur dioxide has been associated with various morbidities demonstrated by controlled exposure experiments conducted in the early 1950's [11] [12]. Epidemiological studies have reported that some sulfur dioxide exposures may be associated with respiratory irritation, bronchoconstriction and have the potential for causing respiratory and pulmonary changes and cardiovascular abnormalities in both healthy and asthmatic individuals [12] [13] [14] [15] [16]. The controlled experiments in the 1950s examined the effects of $\mathrm{SO}_{2}$ inhalation using controlled exposure experiments on healthy individuals. These studies revealed considerable inter-individual variability among healthy individuals however bronchoconstriction responses in most were induced at levels approaching 5 $\operatorname{ppm}\left(10,480-13,100 \mu \mathrm{g} / \mathrm{m}^{3}\right)$. 
The short term effects from sulfur dioxide exposure at much lower and more plausible episodic concentrations between 0.20 and $1 \mathrm{ppm}\left(524-2620 \mu \mathrm{g} / \mathrm{m}^{3}\right)$ were also evaluated using controlled chamber experiments in normal, atopic and asthmatic volunteers [16] [17]. Normal and atopic volunteers showed little response at these levels, whereas some atopic volunteers and most of the asthmatics developed bronchoconstriction and respiratory symptoms. Even at elevated ventilation during exercise, there has been limited evidence of $\mathrm{SO}_{2}$ induced respiratory effects in normal, healthy subjects following short-term exposures of $\leq$ $1 \mathrm{ppm}\left(2620 \mu \mathrm{g} / \mathrm{m}^{3}\right)$ [12] [15] [16] [17]. Bronchoconstriction and compromised lung function tend to occur at lower concentrations $\left(\leq 0.4 \mathrm{ppm}\right.$ or $\left.1048 \mu \mathrm{g} / \mathrm{m}^{3}\right)$ in asthmatic and some atopic individuals, with some reports of symptoms occurring as low as $0.10 \mathrm{ppm}\left(262 \mu \mathrm{g} / \mathrm{m}^{3}\right)$ when combined with exercise or another irritant (i.e., ozone) [14] [15] [16] [18] [19] [20]. The respiratory responses in healthy, atopic or asthmatic subjects can also be increased by exercise and oral ventilation [15] [16] [20] [21] [22]. Several epidemiological studies have also reported some associations between some $\mathrm{SO}_{2}$ exposures and mortality. However, there are many inconsistencies between studies and the measures of association are often not strong enough to suggest mortality risks.

The objective of this study was to conduct an exposure assessment for ambient levels of $\mathrm{SO}_{2}$ downwind of an oil refinery (Isla Refineriá) in Curaçao. This was accomplished by analyzing hourly, daily, and monthly $\mathrm{SO}_{2}$ measurements over a four year period (2010-2014) to determine if any temporal trends exist and to compare levels with public health guidelines in order to assess potential public health risks in Curaçao.

\section{Methods}

\subsection{Site Selection}

Approximately 40 miles off the coast of Venezuela lies the island of Curaçao in the southern Caribbean. Curaçao is located in the Southern Caribbean Dry Zone, which is characterized by a semi-arid to arid climate, with a distinguishable dry and rainy season, and sustained easterlies. The island is approximately 59 kilometers in length, 4 - 11 kilometers wide and a total land mass area of $\sim 443$ $\mathrm{km}^{2}$. The population of $\sim 152,000$ consists of greater than 50 nationalities with Dutch and Papiamento as the official languages. The majority of the population $(>130,000)$ resides in Willemstad which is home to the Isla Refineriá.

\subsection{Air Quality and Meteorological Parameters}

Two air monitoring stations, Beth Chaim and Kas Chikitu, commissioned by the government of Curaçao have been collecting validated and continuous measurements of air quality parameters $\left(\mathrm{SO}_{2}, \mathrm{PM}_{10}, \mathrm{TSP}, \mathrm{H}_{2} \mathrm{~S}\right)$ since mid-2010. The Beth Chaim station is located at the western edge, downwind of the Schottegat industrial area of the refinery and only measures $\mathrm{SO}_{2}$ and TSP. Kas Chikitu is located approximately $2-3 \mathrm{~km}$ downwind in the Marchena/Wishi residential 
area and is primarily used to monitor the residential load of $\mathrm{SO}_{2}$, hydrogen sulfide $\left(\mathrm{H}_{2} \mathrm{~S}\right)$ and $\mathrm{PM}_{10}$. Available hourly and daily measurements of $\mathrm{SO}_{2}$ were downloaded from June 1, 2010 through December 31, 2014 for analysis from the Kas Chikitu station. Twenty-four hour $\mathrm{SO}_{2}$ daily means were downloaded from the Beth Haim station $(n=1605)$ and the Kas Chikitu station $(n=1622)$. Monitoring stations operate in accordance with the ISO/IEC 17025 accreditation (certificate number L 426) of GGD Amsterdam using ultraviolet fluorescence (Thermo 43i-TLE and Thermo 450i Gas Analyzer) methodology to measure $\mathrm{SO}_{2}$. Daily meteorological data (i.e., temperature, precipitation, humidity, wind speed) in Curacao was downloaded from the Tutiempo Network from January 1, 2010 through December 31, 2014.

\subsection{Data Analysis}

All $\mathrm{SO}_{2}$ data is expressed in $\mu \mathrm{g} / \mathrm{m}^{3}$. All data analysis was performed using Statistica Version 6.1 (Stat Soft, Inc., Tulsa, OK). If data did not meet the assumptions of normality, nonparametric hypothesis tests were performed. If a potential explanatory variable was categorical (e.g., year), the nonparametric Kruskal-Wallis ANOVA was run using $\alpha=0.05$. If the Kruskal-Wallis ANOVA was found to be significant multiple comparisons revealed significant differences between categorical factors. Concentrations of $\mathrm{SO}_{2}$ were compared daily and annually and correlations were also evaluated against environmental factors (i.e., temperature, precipitation, humidity and wind speed).

\section{Results and Discussion}

\subsection{Ambient Concentrations of Sulfur Dioxide}

Daily $\mathrm{SO}_{2}$ mean concentrations were downloaded from two local air stations in Curaçao, Beth Haim $(\mathrm{n}=1605)$ and Kas Chikitu $(\mathrm{n}=1622)$. The 24-hour daily mean concentrations ranged from 0.2 to $449 \mu \mathrm{g} / \mathrm{m}^{3}$ and 6.8 to $139 \mu \mathrm{g} / \mathrm{m}^{3}$ at the Beth Haim and Kas Chikitu stations, respectively (Figure 1). Mean annual concentrations at the Beth Haim station ranged from $38.9 \mu \mathrm{g} / \mathrm{m}^{3}$ in 2010 to 170.4 $\mu \mathrm{g} / \mathrm{m}^{3}$ in 2014 (Figure 2). Similar, statistically significant temporal trends were observed at the Beth Haim station with a moderately strong increasing trend $\left(\mathrm{R}^{2}\right.$ $=0.86$ ) over time. Mean annual SO2 concentrations at the Kas Chikitu station ranged from $35.6 \mu \mathrm{g} / \mathrm{m}^{3}$ in 2010 to $55.5 \mu \mathrm{g} / \mathrm{m}^{3}$ in 2014 , also illustrating a moderately strong increasing trend $\left(\mathrm{R}^{2}=0.86\right)$ over time (Figure 2$)$. Increasing trends in $\mathrm{PM}_{10}$ concentrations downwind of the refinery were also reported (Pulster, unpublished data).

\subsection{Global Comparison of $\mathrm{SO}_{2}$}

Annual concentrations measured at the Beth Haim station increased 338\% since 2010 and $36 \%$ since 2011. Similarly, annual concentrations increased at the Kas Chikitu station 36\% since 2010 and $17 \%$ since 2011. Conversely, global trends for $\mathrm{SO}_{2}$ have illustrated decreases. For instance, a 50\% decrease in annual 


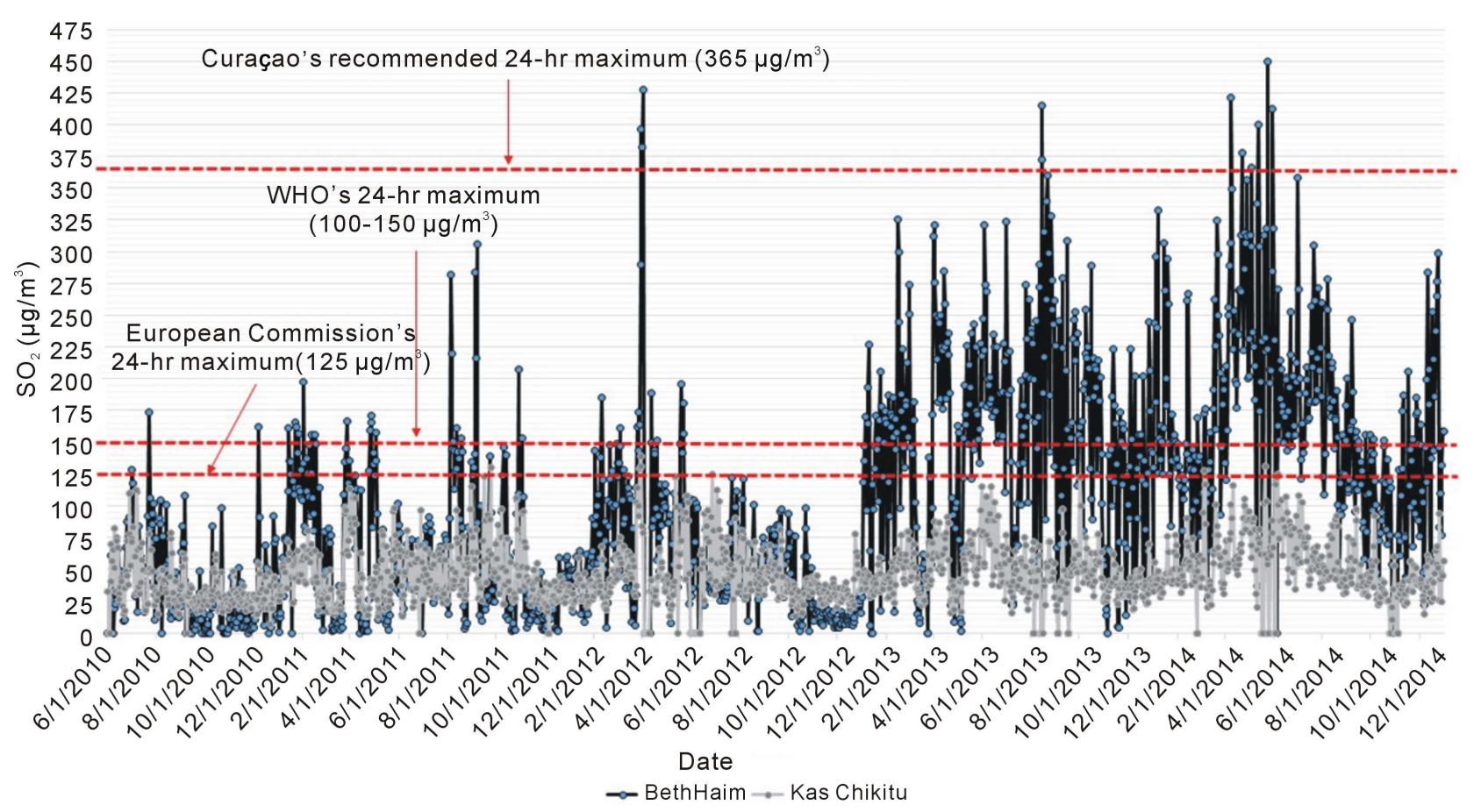

Figure 1. Daily 24-hour mean concentrations of $\mathrm{SO}_{2}\left(\mu \mathrm{g} / \mathrm{m}^{3}\right)$ measured at the Beth Haim and Kas Chikitu air monitoring stations in Curaçao from June 1, 2010 through December 31, 2014.

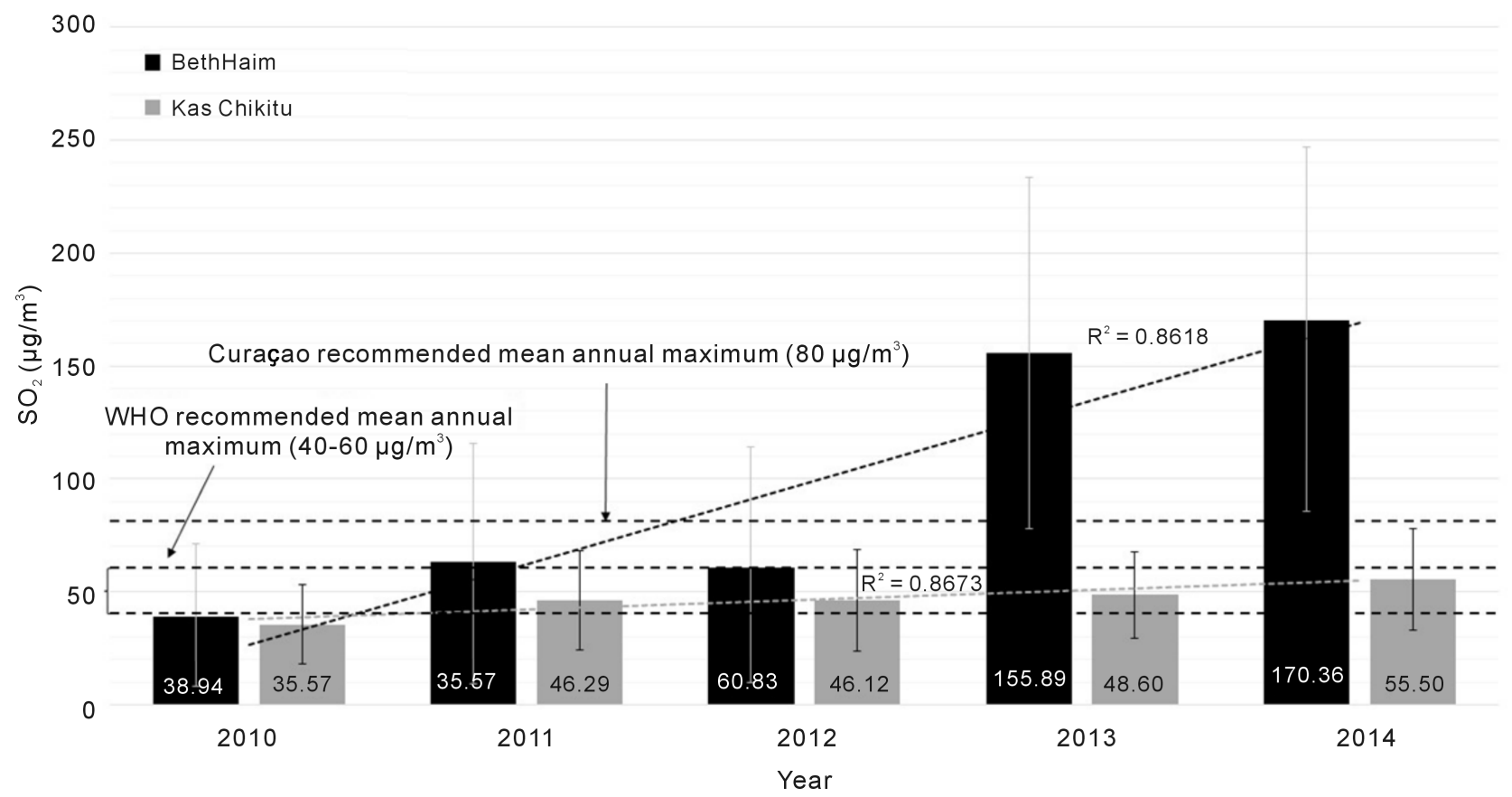

Figure 2. Mean annual $\mathrm{SO}_{2}$ concentrations $\left(\mu \mathrm{g} / \mathrm{m}^{3}\right)$ measured at Beth Haim $(\bullet)$ and Kas Chikitu $(\varpi)$ demonstrate significant temporal trends for the years 2010 through 2014.

average $\mathrm{SO}_{2}$ concentrations was reported in the Yangtze Delta region of eastern China (2005-2010) and in Europe (2001-2010) [23] [24]. The US also reported an $81 \%$ decrease in the daily one hour maximum average for $\mathrm{SO}_{2}$ concentrations 
from 1980-2013 [25]. Decreases were also observed in annual $\mathrm{SO}_{2}$ concentrations in Mexico City with an 84\% decrease between 1986 and 2003 [26]. The annual $\mathrm{SO}_{2}$ concentrations measured at both the Beth Haim and Kas Chikitu station for the years 2010-2014 are among the highest reported globally (Figure 3). The 2014 concentrations measured at Beth Haim were more than 200 times greater than those measured in Nuraminis, Italy $\left(0.72 \mu \mathrm{g} / \mathrm{m}^{3}\right)$ in 2012 (http://www.eea.europa.eu). In addition, the 2013 annual $\mathrm{SO}_{2}$ concentrations $\left(155.9 \mu \mathrm{g} / \mathrm{m}^{3}\right)$ at the Beth Haim station were over 5 times higher than the 2013 US annual average $\left(29.4 \mu \mathrm{g} / \mathrm{m}^{3}\right)$.

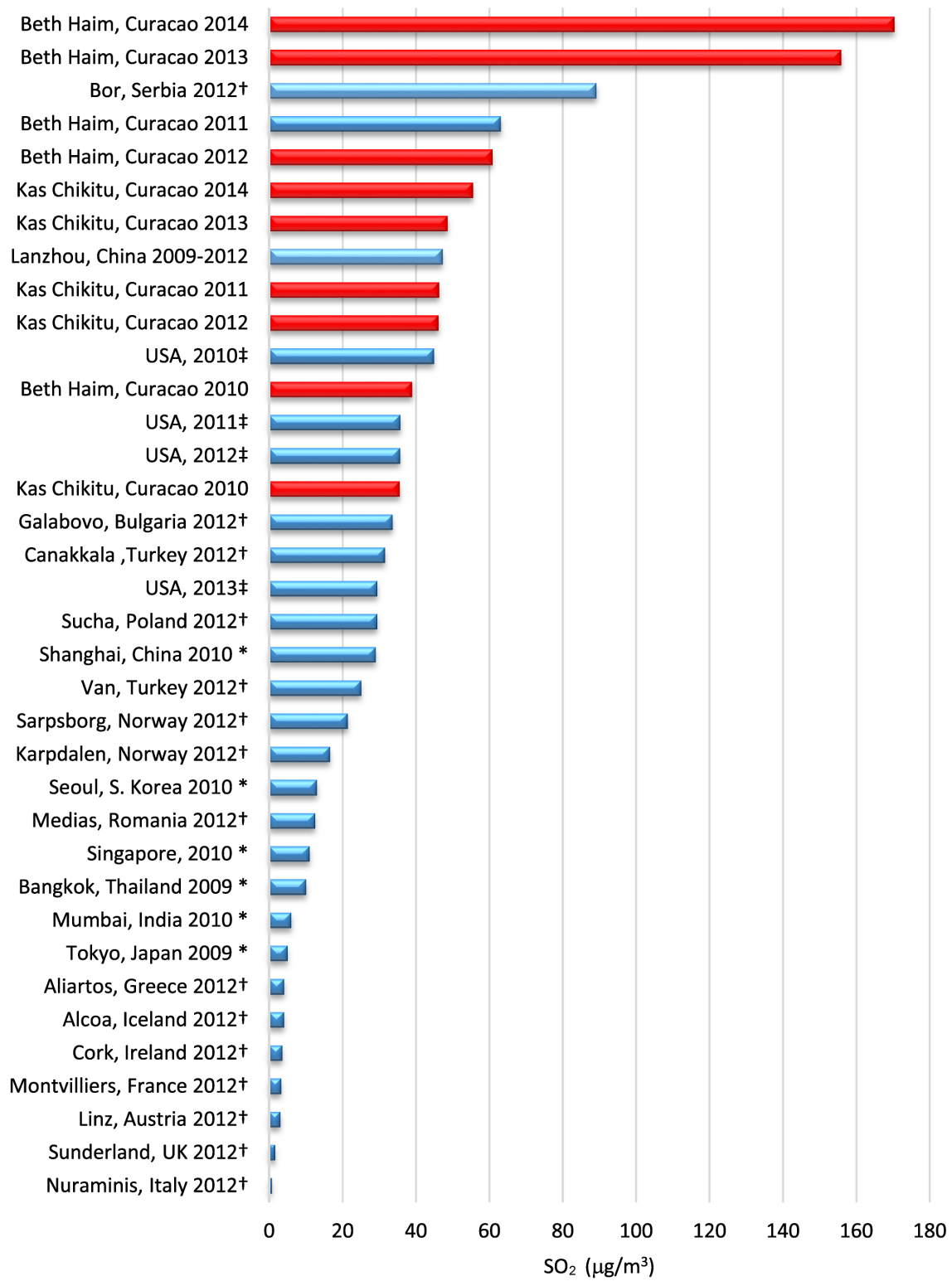

Figure 3. Global comparison of mean annual $\mathrm{SO}_{2}$ concentrations $\left(\mu \mathrm{g} / \mathrm{m}^{3}\right)$. Sources for the concentrations from other countries are as follows †European Environment Agency, ‡USEPA and ${ }^{\star}$ Clean Air Asia Citites ACT. Red bars indicate data relevant to current study. 


\section{3. $\mathrm{SO}_{2}$ Compliance with Public Health Guidelines}

The maximum annual mean concentrations for $\mathrm{SO}_{2}$ that are currently recommended by Curaçao and WHO are $80 \mu \mathrm{g} / \mathrm{m}^{3}$ and between $40-60 \mu \mathrm{g} / \mathrm{m}^{3}$, respectively. The $\mathrm{SO}_{2}$ annual mean concentrations in 2010, at both the Beth Haim (38.9 $\left.\mu \mathrm{g} / \mathrm{m}^{3}\right)$ and Kas Chikitu $\left(35.6 \mu \mathrm{g} / \mathrm{m}^{3}\right)$ air stations, was the only year concentrations were less than the recommended guidelines, however, it is important to note the measurements were only for a 7 month period (July-December). The 24-hour guidelines issued by the European Commission and Curaçao both recommend $125 \mu \mathrm{g} / \mathrm{m}^{3}$ with three permissible excursions. Curaçao recommends the mean 24-hour maximum concentrations do not exceed $365 \mu \mathrm{g} / \mathrm{m}^{3}$ more than once per year. In addition, WHO recommends 24-hour maximum concentrations of $100-150 \mu \mathrm{g} / \mathrm{m}^{3}$. The number of days that exceed the 24-hour guidelines at both stations are also increasing over time. The 24-hour recommended $\mathrm{SO} 2$ guidelines were within compliance for the majority of 2010 (95\%), 2011 (78\%) and $2012(84 \%)$ at the Beth Haim Station (Figure 4). However, 2013 and 2014 exceeded the recommended $\mathrm{SO}_{2}$ guidelines $74 \%$ and $81 \%$ of the year, respectively. Curaçao allows three excursions per year above the 24-hour maximum recommendation $\left(125 \mu \mathrm{g} / \mathrm{m}^{3}\right)$. In 2011, 2012, 2013, and 2014 this value was exceeded 30, 15, 40 and 54 times, respectively. In contrast, the daily $\mathrm{SO}_{2}$ concentrations measured at the Kas Chikitu station were compliant for the majority of each of the years measured in this study [2010 (99\%). 2011 (98\%), 2012 (96\%), 2013 (98\%) and 2014 (95\%)]. The only year that exceeded the number of permissible excursions was 2012, with a total of 4 days exceeding $125 \mu \mathrm{g} / \mathrm{m}^{3}$.

\subsection{Potential Risks of $\mathrm{SO}_{2}$ Inhalation}

Many epidemiological studies have reported relative risk (RR) estimates, hazard ratios (HR) and odds ratios (OR) for associations between mortality and morbidity and $\mathrm{SO}_{2}$, yet results are somewhat inconclusive (Figures 5-7) [27]-[41]. This study primarily focused on literature published within the last five years since there are several meta-analyses and reviews covering literature published prior to 2010.

Many of the studies reported relative risk estimates that were either close to or included unity or had large confidence intervals (Figure 5). A study evaluating air pollution effects on residents of central Taiwan, reported positive relative risk estimates (RR: 1.043, 95\% CI: 1.018 - 1.098) for associations between $\mathrm{SO}_{2}(12.6$ $\mu \mathrm{g} / \mathrm{m}^{3}$ winter mean concentration) and all-cause mortality during the winter months [27]. Similarly, the health impacts were assessed in the megacity of Iran and also reported positive associations (RR: 1.004, 95\% CI: $1.003-1.0048$ ) between all-cause mortality and $\mathrm{SO}_{2}$ concentrations $\left(89.2 \mu \mathrm{g} / \mathrm{m}^{3}\right.$ annual mean) [33]. Lai et al. [28] conducted a meta-analysis of research between 1989 and 2010 reporting health effects on Chinese populations in China, Taiwan and Hong Kong, which also resulted in positive associations (RR: 1.007, 95\% CI: 1.0045 1.0097) between $\mathrm{SO}_{2}\left(14-213 \mu \mathrm{g} / \mathrm{m}^{3}\right.$ annual mean) and all-cause mortality. 


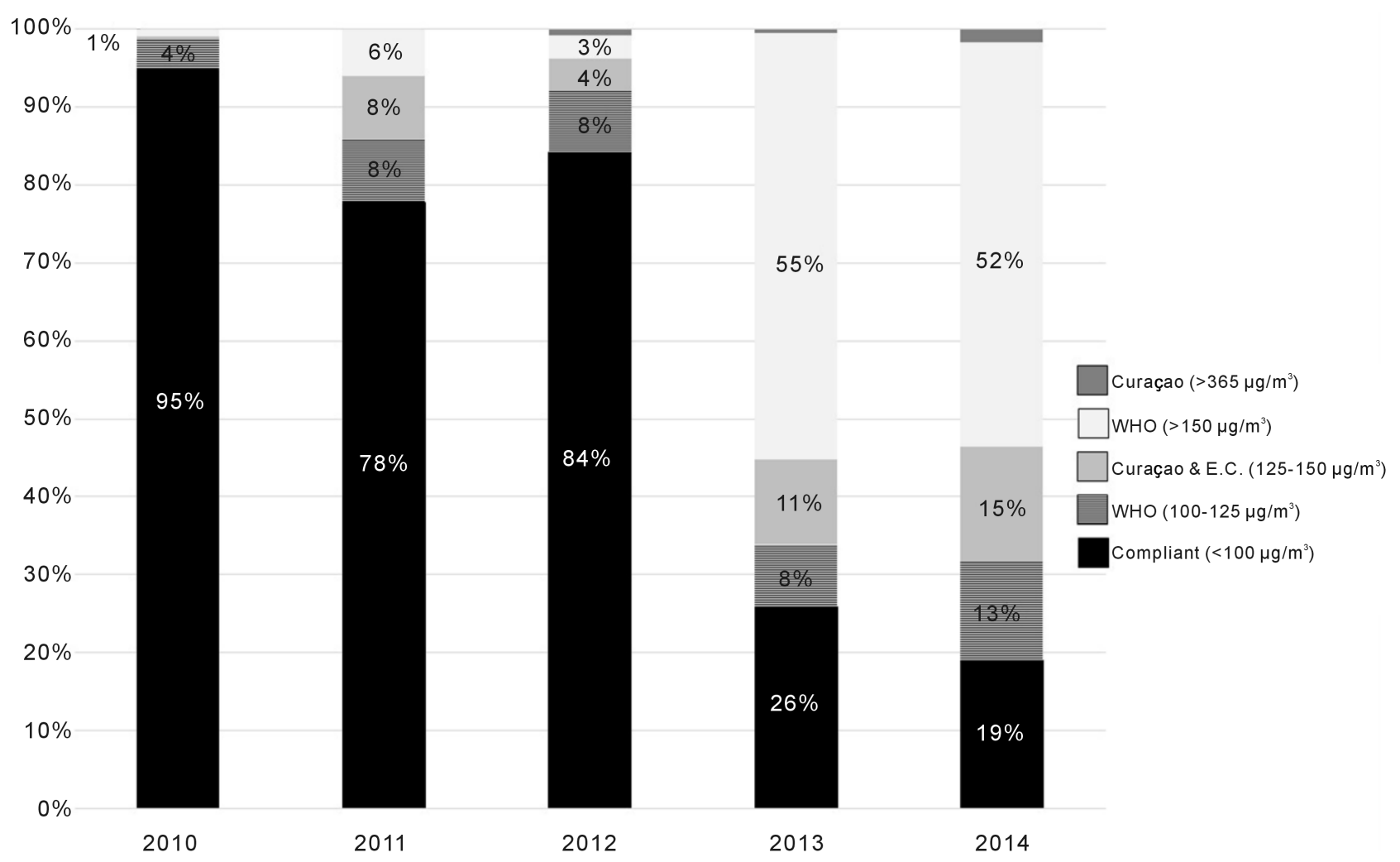

Figure 4. Percentages of each year that were either in compliance or exceeded current maximum 24-hour guidelines for $\mathrm{SO}_{2}$ concentrations at the Beth Haim air monitoring station.

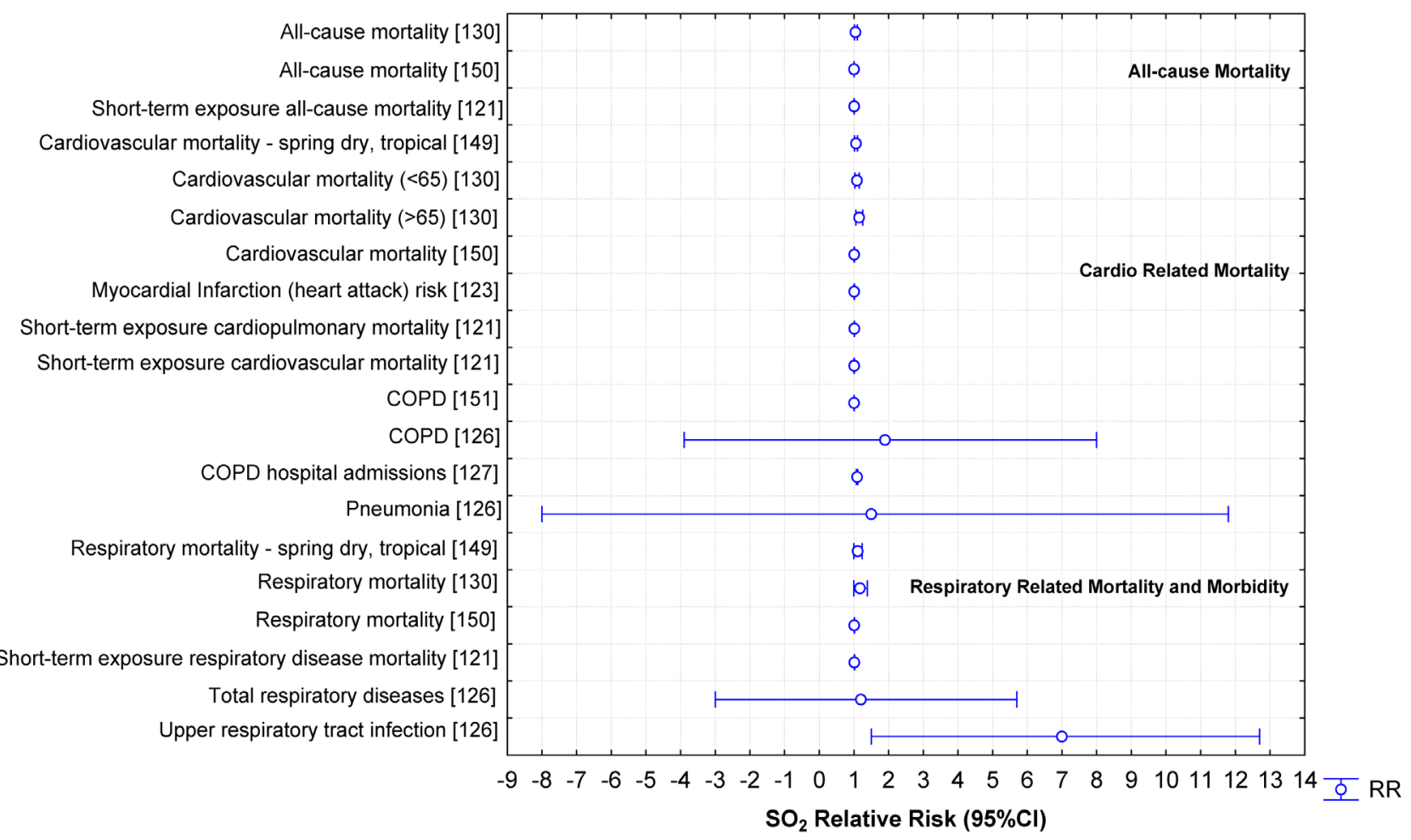

Figure 5. Relative risk estimates $(95 \% \mathrm{CI})$ for $\mathrm{SO}_{2}$ associated mortality and morbidity from published literature. 


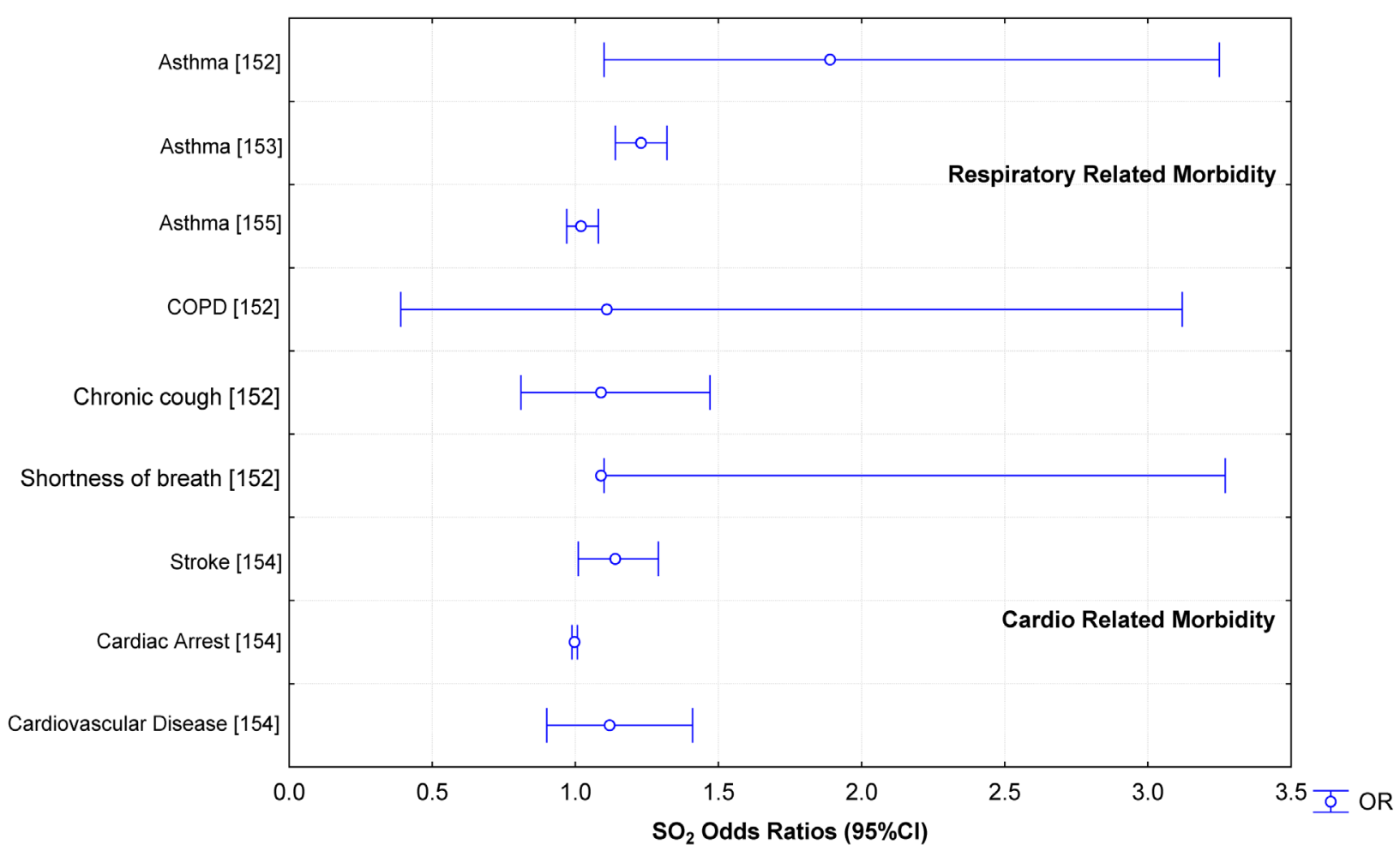

Figure 6. Odds ratios $(95 \% \mathrm{CI})$ for $\mathrm{SO}_{2}$ associated morbidity from published literature.

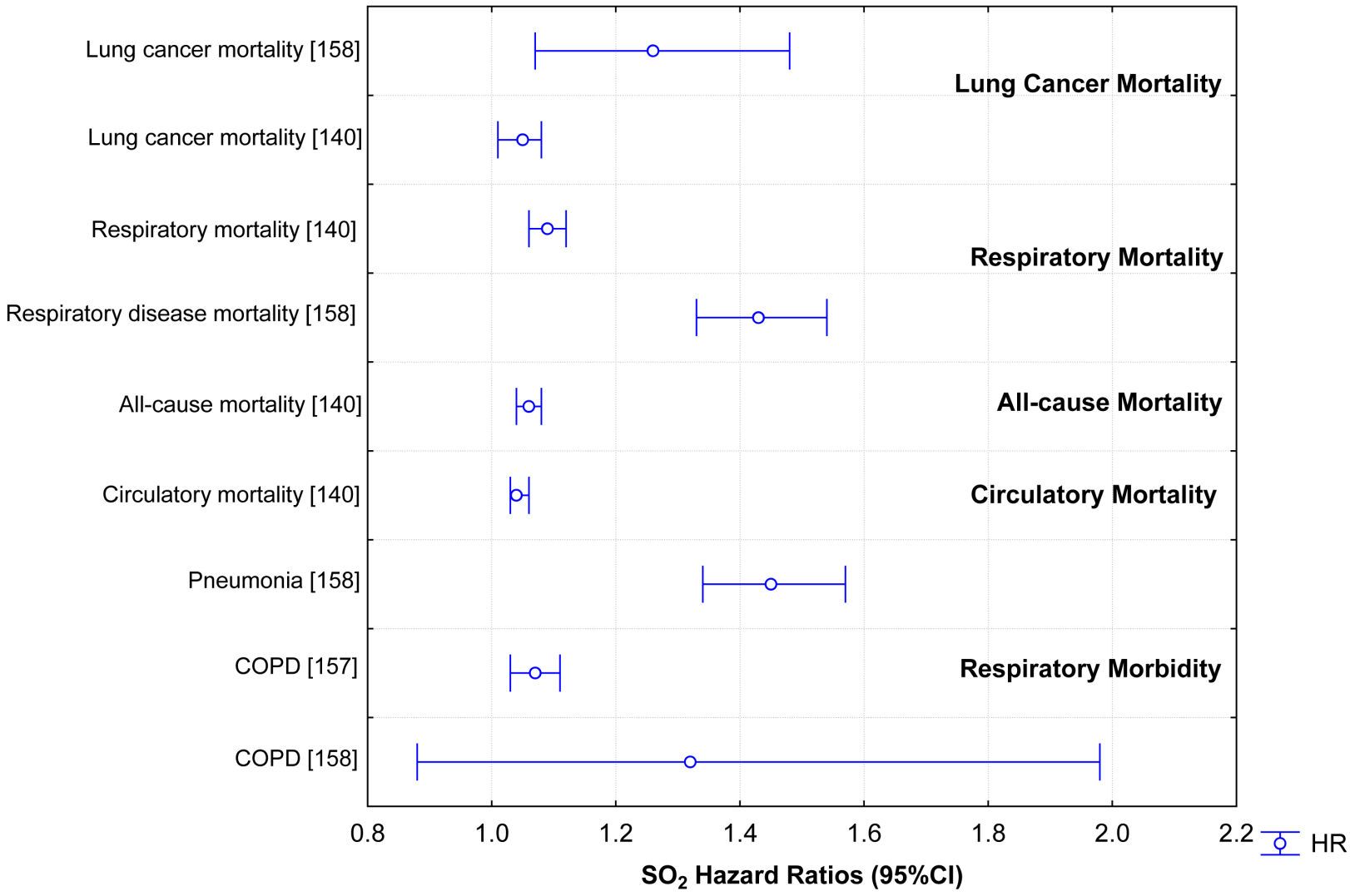

Figure 7. Hazard ratios $(95 \% \mathrm{CI})$ for $\mathrm{SO}_{2}$ associated morbidity from published literature. 
Several studies reported positive associations between $\mathrm{SO}_{2}$ and cardio related mortality and risk [27] [28] [30] [31] [33]. A Canadian study reported positive associations (RR: 1.061, 95\% CI: 1.018 - 1.105) between $\mathrm{SO}_{2}\left(15.72 \mu \mathrm{g} / \mathrm{m}^{3}\right.$ spring mean) and cardiovascular mortality during the spring when the weather was described as dry and tropical [30]. The meta-analysis evaluating air pollution effects on Chinese populations also reported positive associations between short-term $\mathrm{SO}_{2}$ exposure $\left(14-213 \mu \mathrm{g} / \mathrm{m}^{3}\right.$ annual mean) and cardiopulmonary (RR: 1.01, 95\% CI: 1.009 - 1.015) and cardiovascular mortality (RR: 1.007, 95\% CI: 1.004 - 1.01) [28]. A meta-analysis of 34 studies concluded statistically significant positive associations (RR: $1.01,95 \% \mathrm{CI}: 1.003$ - 1.017) with $\mathrm{SO}_{2}$ and increased risks of myocardial infarction [31].

The relative risks reported for chronic obstructive pulmonary disease (COPD) and respiratory mortality or morbidity appear to be likewise inconclusive. Significant positive associations between $\mathrm{SO}_{2}$ and COPD were reported in Shiraz $\left(674.9 \mu \mathrm{g} / \mathrm{m}^{3}\right.$ annual mean; RR: 1.095, 95\% CI: $\left.1.07-1.11\right)$ and Tabriz, Iran (19 $\mu \mathrm{g} / \mathrm{m}^{3}$ annual mean; RR: 1.0044, 95\% CI: 1.0 - 1.011) [32] [34]. In contrast, a study reported no significant associations (RR: 1.9, 95\% CI: 0.9 - 8) with COPD in the heavily polluted city of Lanzhou, China where the mean $\mathrm{SO}_{2}$ concentrations $\left(79 \mu \mathrm{g} / \mathrm{m}^{3}\right.$ annual mean) are four times higher than those reported in Tabriz, Iran and almost an order of magnitude lower than those reported in Shiraz, Iran [29]. No significant associations were found between respiratory mortality and $\mathrm{SO}_{2}$ in Canada (RR: 1.11, 95\% CI: 0.996 - 1.238) and Taiwan (RR: 1.176, 95\% CI: 0.998-1.384) [27] [30]. In contrast, significant positive associations were reported in Iran (RR: 1.01, 95\% CI: 1.006 - 1.014) and in a 26 study meta-analysis study (RR: 1.012, 95\% CI: 1.0058 - 1.0199) [28] [33].

A number of studies also reported odds ratios for various morbidities (Figure 6). Amster et al. [35] reported positive associations between asthma (OR: 1.89, 95\% CI: 1.1 - 3.25) and shortness of breath (OR: 1.09, 95\% CI: 1.1 - 3.27) with total ambient $\mathrm{SO}_{2}$ concentrations of $6.6 \mu \mathrm{g} / \mathrm{m}^{3}$, yet interestingly, no significant associations were observed with higher $\mathrm{SO}_{2}\left(43 \mu \mathrm{g} / \mathrm{m}^{3}\right)$ concentrations related to specific coal-fired power plant events. A meta-analysis evaluating effects from long-term air pollution exposure reported no significant associations (OR: 1.02, 95\% CI: 0.97 - 1.08) between $\mathrm{SO}_{2}$ and asthma prevalence and wheezing in children [38]. Conversely, in a cross-sectional study consisting of over 23,000 Chinese children, significant positive associations (OR: 1.23 , 95\% CI: 1.14 - 1.32) were reported between $\mathrm{SO}_{2}\left(50.3 \mu \mathrm{g} / \mathrm{m}^{3}\right.$ annual mean) and asthma [36].

The hazard ratios reported for mortality and various respiratory morbidities also illustrated weak and inconsistent associations with $\mathrm{SO}_{2}$ and various endpoints (Figure 7). The National English Cohort study, consisting of over 800,000 participants, reported statistically significant positive associations (HR: 1.05, 95\% CI: 1.01 - 1.08) between lung cancer mortality and $\mathrm{SO}_{2}$ [42]. Similarly, a Japanese cohort study, consisting of over 63,000 study participants, also reported significant positive associations (HR: 1.26, 95\% CI: 1.07 - 1.48) between lung 
cancer mortality and $\mathrm{SO}_{2}$, although the confidence interval range is relatively wide [41]. Hazard ratios were also reported for respiratory mortality and COPD. Both a National English Cohort (HR: 1.09, 95\% CI: 1.06 - 1.12) and the Japanese Cohort (HR: 1.43, 95\% CI: 1.33 - 1.54) studies reported significant positive associations between $\mathrm{SO}_{2}$ and respiratory mortality [41] [42]. For COPD, significant associations were reported in a National English Cohort study (HR: 1.07, 95\% CI: 1.03 - 1.11) yet no significant associations (HR: 1.32, 95\% CI: 0.88 - 1.98) were reported in the Japanese cohort study [40] [41].

In summary, the epidemiological studies presented a mix of weak positive associations (i.e., $\mathrm{RR}, \mathrm{HR}, \mathrm{OR}<3.0$ ) between health effects and $\mathrm{SO}_{2}$ and nonsignificant findings. Potential inconsistencies between studies and results could be due to confounding factors with copollutants and various study designs and methodology, making individual findings difficult to interpret and inconclusive as to the effect of observed levels of $\mathrm{SO}_{2}$ on health. In general, cardiovascular and respiratory effects and mortality were evaluated in locations with a wide range in annual mean concentrations ranging from 4 to $675 \mu \mathrm{g} / \mathrm{m}^{3}$.

Evidence regarding short-term exposures to $\mathrm{SO}_{2}$ were inadequate to infer an association with cardiovascular health [43]. As well, the available evidence was inadequate to infer an association between long-term $\mathrm{SO}_{2}$ exposures and respiratory effects (including asthma), cardiovascular effects and mortality. In the selected epidemiological studies evaluated in a USEPA review, associations between short-term $\mathrm{SO}_{2}$ exposures and some respiratory effects were observed in locations with mean 24-hour average $\mathrm{SO}_{2}$ concentrations ranging from 2.62 to $78.6 \mu \mathrm{g} / \mathrm{m}^{3}$, with maximum values ranging from 31.4 to $196.5 \mu \mathrm{g} / \mathrm{m}^{3}$. In addition, some associations with mortality were observed with mean 24-hour average $\mathrm{SO}_{2}$ concentrations less than $26.2 \mu \mathrm{g} / \mathrm{m}^{3}$.

\subsection{Meteorological Parameters and $\mathrm{SO}_{2}$ Concentrations}

Daily temperature, humidity, precipitation and wind speeds were analyzed for trends and correlations with $\mathrm{SO}_{2}$ concentrations. Briefly, the mean temperature ( \pm standard deviation) from 2010 through 2014 was $27.9^{\circ} \mathrm{C}( \pm 1.2)$ and although Kruskal-Wallis multiple comparisons revealed annual differences $(\mathrm{p}<0.000001)$ there were no observable trends $\left(\mathrm{R}^{2}=0.0007\right)$. The mean humidity $(77.7 \% \pm$ $\left.4.1 \% ; \mathrm{R}^{2}=0.73\right)$ and precipitation $\left(1.70 \pm 6.9 \mathrm{~mm} ; \mathrm{R}^{2}=0.75\right)$ from 2010 through 2014 both demonstrated moderately strong decreasing trends. Mean annual wind speeds $(19.6 \pm 4.7 \mathrm{~km} / \mathrm{h})$ demonstrated a strong increasing trend over time $\left(\mathrm{R}^{2}=0.91\right)$. This is consistent with increasing global trends in wind speed [44]. Similar to observations seen with $\mathrm{PM}_{10}$ concentrations (Pulster, unpublished data), there was a weak to moderately strong correlation between $\mathrm{SO}_{2}$ concentrations and wind speeds at Beth Haim $(r=0.42)$ and the Kas Chikitu $(r=0.46)$ station (Figure 8). In addition, $\mathrm{SO}_{2}$ concentrations were found to have a weak, negative correlation with humidity (Beth Haim $r=-0.37$; Kas Chikitu $r=-0.29$ ) and precipitation (Beth Haim $r=-0.12$; Kas Chikitu $r=-0.15$ ) at both stations. 


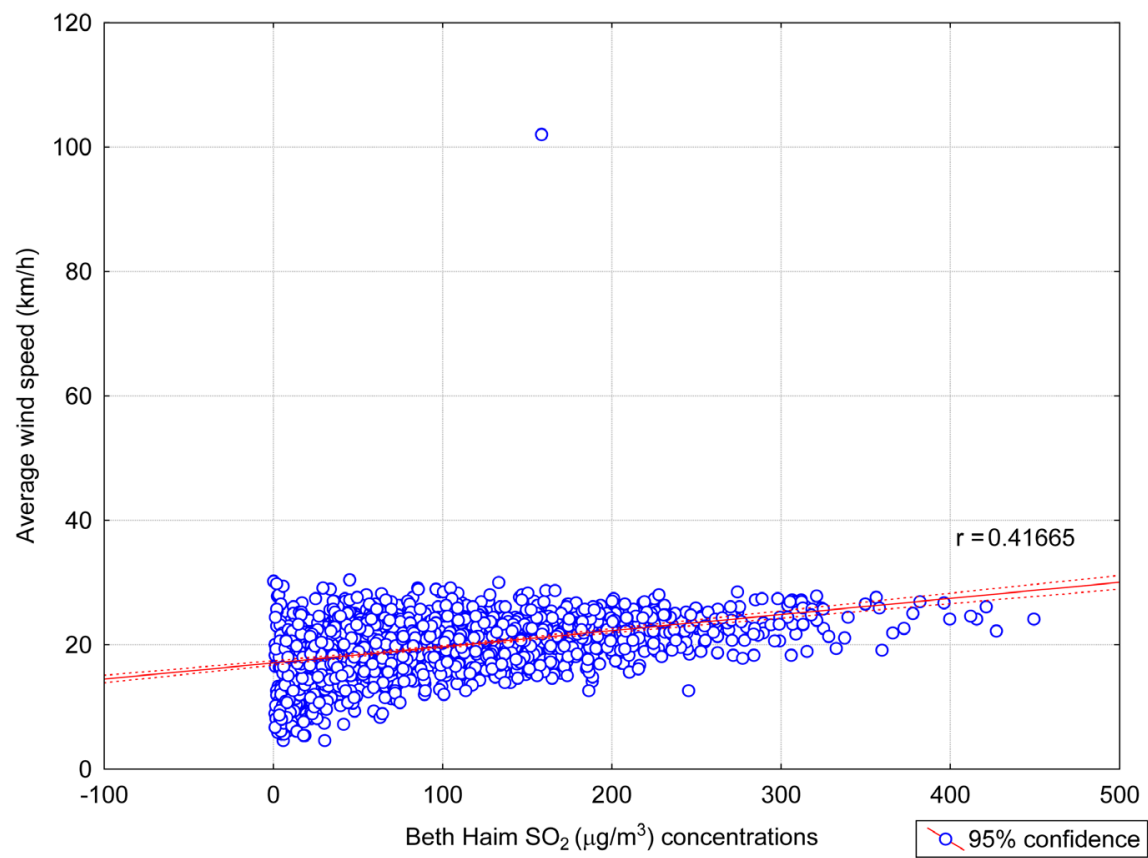

(a)

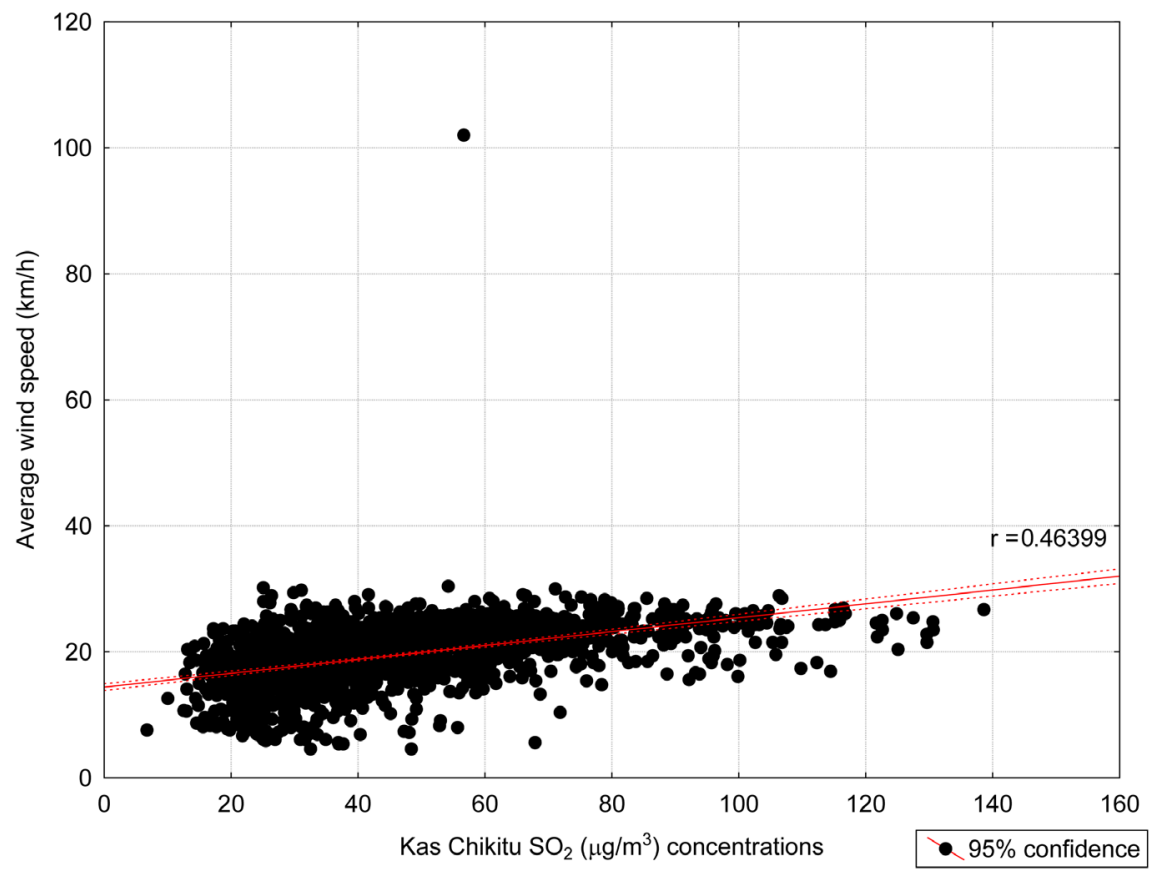

(b)

Figure 8. Regression analysis between wind speeds $(\mathrm{km} / \mathrm{h})$ and $\mathrm{SO}_{2}$ concentrations $\left(\mu \mathrm{g} / \mathrm{m}^{3}\right)$ at the Beth Haim (a) and the Kas Chikitu (b) air monitoring station measurements from 2010 through 2014.

There were no correlations found between $\mathrm{SO}_{2}$ and temperature at either the Beth Haim $(r=0.11)$ or the Kas Chikitu $(r=0.15)$ station. This is not surprising since the average year round temperature is $\sim 28^{\circ} \mathrm{C}$ with very little fluctuation. 
Meteorological parameters can influence air pollution concentrations in ambient air, for instance, the frequencies and concentrations of pollution episodes can vary considerably over time and space depending on weather, which indicates the importance of climate change [45] [46]. In some instances, wind speeds can have a dilution effect which has been demonstrated in a study in Hungary, that illustrated increasing wind speeds decreased aerosol concentrations which resulted in decreased pollen related hospital admissions [47]. However, other studies have demonstrated statistically significant impacts from $\mathrm{SO}_{2}$ and other emissions downwind of oil and gas exploration and production activities [46]. Likewise, this study illustrates that increasing wind speeds were correlated with increasing $\mathrm{SO}_{2}$ concentrations downwind of the Isla Refineriá's plume trajectory in Curaçao. Furthermore, the previously reported increasing inhalable particulate matter in this region mimics that of the $\mathrm{SO}_{2}$ suggesting a single source (Figure 9; Pulster, unpublished data). This suggests with increasing wind speeds, pollution plumes and fluxes are also expected to increase, ultimately impacting local populations residing within the refinery's plume trajectory.

\section{Conclusions}

The objective of this investigation was to conduct an exposure assessment by analyzing levels of $\mathrm{SO}_{2}$ in ambient air surrounding Willemstad, Curaçao in order to determine if any temporal trends exist in the measured concentrations, to verify if measured levels exceed current public health guidelines and to identify potential health risks. In conclusion, concentrations of $\mathrm{SO}_{2}$ in Curaçao are among the highest reported globally and demonstrate an increasing trend over time. Levels of $\mathrm{SO}_{2}$ exceeded the annual and 24-hour guidelines recommended by Curaçao, the European Commission, and the World Health Organization.

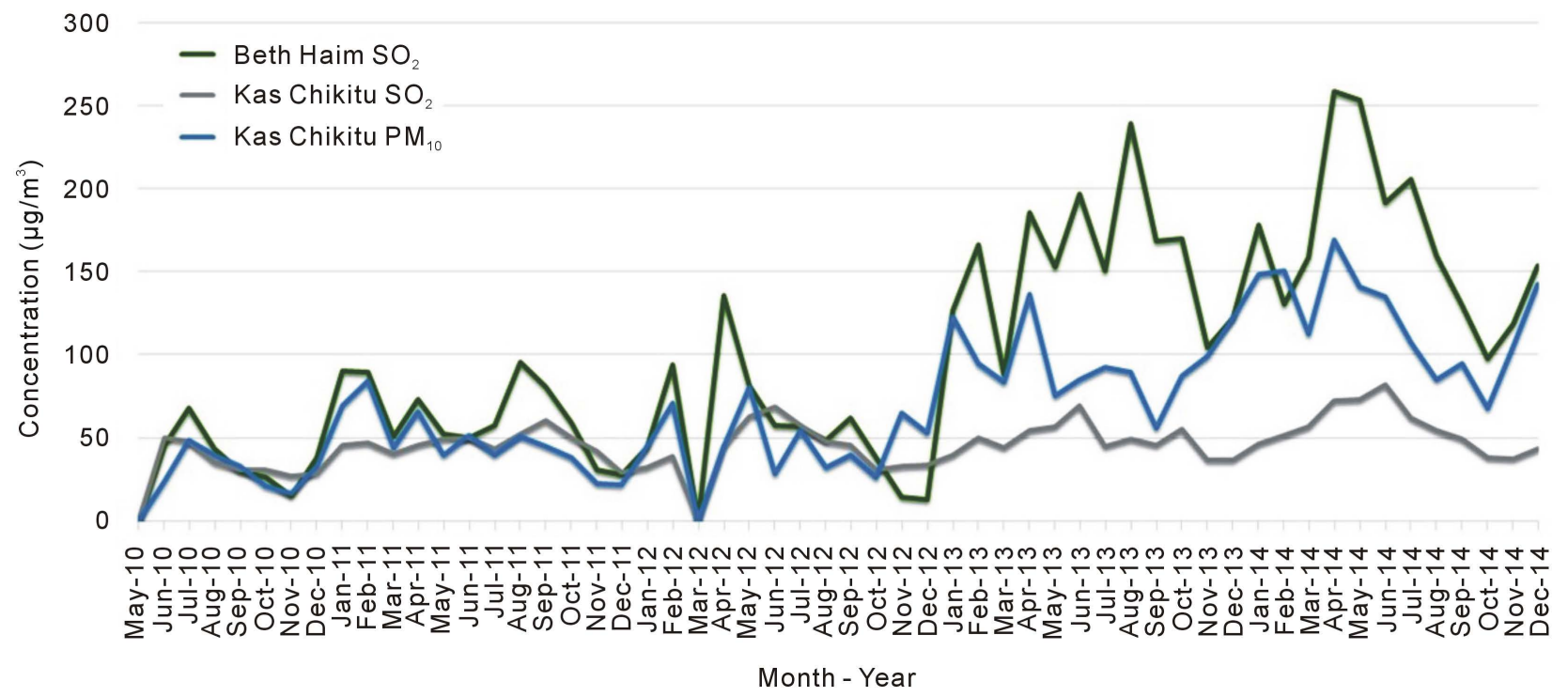

Figure 9. Increasing trends of monthly measurements of $\mathrm{SO}_{2}$ and $\mathrm{PM}_{10}$ at the Beth Haim and Kas Chikitu air stations in Curaçao from 2010 through 2014, suggesting one source. 
Furthermore, both the 24-hour and annual mean concentrations of $\mathrm{SO}_{2}$ measured in Curaçao were within the ranges often associated with cardiovascular and respiratory effects and mortality as a result of short-term exposures. While the epidemiological evidence does not conclusively suggest there is a health risk from these levels of exposure, $\mathrm{SO}_{2}$ concentrations greatly exceed regulatory and guidance levels and suggest that further emissions control is warranted.

In a recent survey, $60 \%$ of 3230 children (ages 0 - 14) in Curaçao had asthma, which is more than four times the global average for children [48]. Since exposures to both $\mathrm{SO}_{2}$ and $\mathrm{PM}_{10}$, individually and together, have been found to be associated with significant increases in the prevalence of pediatric asthma and asthma related hospital admissions, this should necessitate the need for further evaluation [49] [50]. This warrants a more rigorous epidemiological study in Curaçao involving clinical assessments to evaluate health effects and disease associations with air quality parameters. A complete human health risk assessment is recommended to include dermal, inhalation and dietary exposure pathways. Future research needs in Curaçao include expanding the air monitoring efforts to include areas upwind of the refinery as well as additional petrochemical emissions, including but not limited to sulfur dioxide, particulate matter $\left(\mathrm{PM}_{10}\right.$ and $\mathrm{PM}_{2.5}$ ), benzene, as well as both the vapor and particulate phases of ambient PAHs.

\section{Acknowledgements}

The authors wish to thank the Environmental Fund Netherlands Antilles (MINA Fund) and Mote Marine Laboratory for the financial support of this work. We are most grateful to George Keiffer (Curaçao Sea Aquarium), Gerard VanBuurt, Tone Moller (Avila Hotel) and the residents of Curaçao for the logistical support and for providing valuable insights and local knowledge to help us understand some of the societal issues and impacts from Isla Refineria on local communities.

\section{References}

[1] WHO (2006) Air Quality Guidelines Global Update 2005: Particulate Matter, Ozone, Nitrogen Dioxide and Sulfur Dioxide. W.R.O.f. Europe, Copenhagen.

[2] Speidel, M., et al. (2007) Sulfur Dioxide Measurements in the Lower, Middle and Upper Troposphere: Deployment of an Aircraft-Based Chemical Ionization Mass Spectrometer with Permanent In-Flight Calibration. Atmospheric Environment, 41, 2427-2437. https://doi.org/10.1016/j.atmosenv.2006.07.047

[3] Smith, S.J., Pitcher, H. and Wigley, T.M.L. (2001) Global and Regional Anthropogenic Sulfur Dioxide Emissions. Global and Planetary Change, 29, 99-119. https://doi.org/10.1016/S0921-8181(00)00057-6

[4] Georgoulias, A.K., et al. (2009) A Study of the Total Atmospheric Sulfur Dioxide Load Using Ground-Based Measurements and the Satellite Derived Sulfur Dioxide Index. Atmospheric Environment, 43, 1693-1701. https://doi.org/10.1016/j.atmosenv.2008.12.012

[5] Chen, T.-M., et al. (2007) Outdoor Air Pollution: Nitrogen Dioxide, Sulfur Dioxide, and Carbon Monoxide Health Effects. American Journal of the Medical Sciences, 
333, 249-256. https://doi.org/10.1097/MAJ.0b013e31803b900f

[6] UNEP (1994) Regional Overview of Land-Based Sources of Pollution in the Wider Caribbean Region. UNEP Caribbean Environment Programme, Kingston, Jamaica.

[7] Van der Torn, P. (1999) Health Complaints \& Air Pollution from the Isla Refinery in Curacao. Public Health Service of Rotterdam and Surrounding, Rotterdam.

[8] Sanhueza, E., Africano, M. and Romero, J. (1982) Air Pollution in Tropical Areas. Science of the Total Environment, 23, 3-10.

https://doi.org/10.1016/0048-9697(82)90115-2

[9] Dunker, P. (2007) Sulfur-Dioxide \& Suspended Particles Ground Level Concentrations Refineria ISLA (Curacao) B.V. Technical Report-S02 \& TSP Ground Level Concentrations Ambient Air Quality Report, 1-13.

[10] ATSDR (1998) Toxicological Profile for Sulfur Dioxide. P.H.S. U.S. Department of Health and Human Services, Ed., U.S. Department of Health and Human Services, Public Health Service, Atlanta, GA, 223.

[11] Amdur, M.O., Melvin, W.W. and Drinker, P. (1953) Effects of Inhalation of Sulphur Dioxide by Man. The Lancet, 265, 758-759.

[12] Lawther, P.J. (1955) Effects of Inhalation of Sulphur Dioxide on Respirtation and Puse-Rate in Normal Subjects. The Lancet, 2, 745-748.

[13] Sunyer, J., et al. (2003) The Association of Daily Sulfur Dioxide Air Pollution Levels with Hospital Admissions for Cardiovascular Diseases in Europe (The Aphea-II Study). European Heart Journal, 24, 752-760.

[14] Tunnicliffe, W.S., et al. (2001) The Effect of Sulphur Dioxide Exposure on Indices of Heart Rate Variability in Normal and Asthmatic Adults. European Respiratory Journal, 17, 604-608. https://doi.org/10.1183/09031936.01.17406040

[15] Johns, D.O. and Linn, W.S. (2011) A Review of Controlled Human $\mathrm{SO}_{2}$ Exposure Studies Contributing to the US EPA Integrated Science Assessment for Sulfur Oxides. Inhalation Toxicology, 23, 33-43.

https://doi.org/10.3109/08958378.2010.539290

[16] Linn, W.S., et al. (1987) Replicated Dose-Response Study of Sulfur Dioxide Effects in Normal, Atopic, and Asthmatic Volunteers. American Review of Respiratory Disease, 136, 1127-1135. https://doi.org/10.1164/ajrccm/136.5.1127

[17] Schachter, E.N., et al. (1984) Airway Effects of Low Concentrations of Sulfur Dioxide: Dose-Response Characteristics. Archives of Environmental Health, 39, 34-42. https://doi.org/10.1080/00039896.1984.10545831

[18] Sheppard, D., et al. (1981) Exercise Increases Sulfur Dioxide-Induced Bronchoconstriction in Asthmatic Subjects. American Review of Respiratory Disease, 123, 486-491.

[19] Koenig, J.Q., et al. (1990) Prior Exposure to Ozone Potentiates Subsequent Response to Sulfur Dioxide in Adolescent Asthmatic Subjects. American Review of Respiratory Disease, 141, 377-380. https://doi.org/10.1164/ajrccm/141.2.377

[20] Johns, D.O., Svendsgaard, D. and Linn, W.S. (2010) Analysis of the Concentration-Respiratory Response among Asthmatics Following Controlled Short-Term Exposures to Sulfur Dioxide. Inhalation Toxicology, 22, 1184-1193. https://doi.org/10.3109/08958378.2010.535220

[21] Speizer, F.E. and Frank, N.R. (1966) A Comparison of Changes in Pulmonary Flow Resistance in Healthy Volunteers Acutely Exposed to $\mathrm{SO}_{2}$ by Mouth and by Nose. British Journal of Industrial Medicine, 23, 75-79.

[22] Stacy, R.W., et al. (1981) Effects of 0.75 ppm Sulfur Dioxide on Pulmonary Function 
Parameters of Normal Human Subjects. Archives of Environmental Health, 36, 172-178. https://doi.org/10.1080/00039896.1981.10667622

[23] Qi, H., et al. (2012) Significant Downward Trend of $\mathrm{SO}_{2}$ Observed from 2005 to 2010 at a Background Station in the Yangtze Delta Region, China. Science China Chemistry, 55, 1451-1458. https://doi.org/10.1007/s11426-012-4524-y

[24] Agency, E.E. (2012) Trend in Average Annual $\mathrm{SO}_{2}$ Concentrations (2001-2010) per Station Type.

http://www.eea.europa.eu/data-and-maps/figures/trend-in-average-annual-so2

[25] USEPA (2014) Sulfur Dioxide. http://www.epa.gov/airtrends/sulfur.html

[26] Hayward, S.F. (2011) Air Quality, in 2011 Almanac of Environmental Trends. Pacific Research Institute, San Francisco, 31-85.

[27] Liang, W.-M., Wei, H.-Y. and Kuo, H.-W. (2009) Association between Daily Mortality from Respiratory and Cardiovascular Diseases and Air Pollution in Taiwan. Environmental Research, 109, 51-58. https://doi.org/10.1016/j.envres.2008.10.002

[28] Lai, H.-K., Tsang, H. and Wong, C.-M. (2013) Meta-Analysis of Adverse Health Effects due to Air Pollution in Chinese Populations. BMC Public Health, 13, 360. https://doi.org/10.1186/1471-2458-13-360

[29] Tao, Y., et al. (2014) Air Pollution and Hospital Admissions for Respiratory Diseases in Lanzhou, China. Environmental Pollution, 185, 196-201. https://doi.org/10.1016/j.envpol.2013.10.035

[30] Vanos, J.K., Hebbern, C. and Cakmak, S. (2014) Risk Assessment for Cardiovascular and Respiratory Mortality due to Air Pollution and Synoptic Meteorology in 10 Canadian Cities. Environmental Pollution, 185, 322-332. https://doi.org/10.1016/j.envpol.2013.11.007

[31] Mustafic, H., et al. (2012) Main Air Pollutants and Myocardial Infarction a Systematic Review and Meta-Analysis. Journal of the American Medical Association, 307, 713-721. https://doi.org/10.1001/jama.2012.126

[32] Gharehchahi, E., et al. (2013) Health Impact Assessment of Air Pollution in Shiraz, Iran: A Two-Part Study. Journal of Environmental Health Science and Engineering, 11, 11. https://doi.org/10.1186/2052-336X-11-11

[33] Naddafi, K., et al. (2012) Health Impact Assessment of Air Pollution in Megacity of Tehran, Iran. Iranian Journal of Environmental Health Science \& Engineering, 9, 28.

[34] Ghozikali, M.G., et al. (2015) Effect of Exposure to O-3, $\mathrm{NO}_{2}$, and $\mathrm{SO}_{2}$ on Chronic Obstructive Pulmonary Disease Hospitalizations in Tabriz, Iran. Environmental Science and Pollution Research, 22, 2817-2823. https://doi.org/10.1007/s11356-014-3512-5

[35] Amster, E.D., et al. (2014) Contribution of Nitrogen Oxide and Sulfur Dioxide Exposure from Power Plant Emissions on Respiratory Symptom and Disease Prevalence. Environmental Pollution, 186, 20-28. https://doi.org/10.1016/j.envpol.2013.10.032

[36] Liu, F., et al. (2014) Asthma and Asthma Related Symptoms in 23,326 Chinese Children in Relation to Indoor and Outdoor Environmental Factors: The Seven Northeastern Cities (SNEC) Study. Science of the Total Environment, 497, 10-17. https://doi.org/10.1016/j.scitotenv.2014.07.096

[37] Dong, G.-H., et al. (2013) Associations between Ambient Air Pollution and Prevalence of Stroke and Cardiovascular Diseases in 33 Chinese Communities. Atmospheric Environment, 77, 968-973. https://doi.org/10.1016/j.atmosenv.2013.06.034 
[38] Anderson, H.R., Favarato, G. and Atkinson, R.W. (2013) Long-Term Exposure to Outdoor Air Pollution and the Prevalence of Asthma: Meta-Analysis of Multi-Community Prevalence Studies. Air Quality Atmosphere and Health, 6, 57-68. https://doi.org/10.1007/s11869-011-0145-4

[39] Straney, L., et al. (2014) Evaluating the Impact of Air Pollution on the Incidence of Out-of-Hospital Cardiac Arrest in the Perth Metropolitan Region: 2000-2010. Journal of Epidemiology and Community Health, 68, 6-12. https://doi.org/10.1136/jech-2013-202955

[40] Atkinson, R.W., et al. (2015) Long-Term Exposure to Outdoor Air Pollution and the Incidence of Chronic Obstructive Pulmonary Disease in a National English Cohort. Occupational and Environmental Medicine, 72, 42-48. https://doi.org/10.1136/oemed-2014-102266

[41] Katanoda, K., et al. (2011) An Association between Long-Term Exposure to Ambient Air Pollution and Mortality from Lung Cancer and Respiratory Diseases in Japan. Journal of Epidemiology, 21, 132-143. https://doi.org/10.2188/jea.JE20100098

[42] Carey, I.M., et al. (2013) Mortality Associations with Long-Term Exposure to Outdoor Air Pollution in a National English Cohort. American Journal of Respiratory and Critical Care Medicine, 187, 1226-1233. https://doi.org/10.1164/rccm.201210-1758OC

[43] USEPA (2008) Integrated Science Assessment (ISA) for Sulfur Oxides (Health Criteria). USEPA, Research Triangle Park.

[44] Young, I.R., et al. (2013) Global Trends in Extreme Wind Speed and Wave Height. Science, 332, 451-455. https://doi.org/10.1115/OMAE2013-10021

[45] Mickley, L.J., et al. (2004) Effects of Future Climate Change on Regional Air Pollution Episodes in the United States. Geophysical Research Letters, 31, L24103. https://doi.org/10.1029/2004GL021216

[46] Cheng, H., Small, M.J. and Pekney, N.J. (2015) Application of Nonparametric Regression and Statistical Testing to Identify the Impact of Oil and Natural Gas Development on Local Air Quality. Atmospheric Environment, 119, 381-392. https://doi.org/10.1016/j.atmosenv.2015.08.016

[47] Matyasovszky, I., et al. (2011) Multivariate Analysis of Respiratory Problems and Their Connection with Meteorological Parameters and the Main Biological and Chemical Air Pollutants. Atmospheric Environment, 45, 4152-4159. https://doi.org/10.1016/j.atmosenv.2011.05.024

[48] Network, G.A. (2014) The Global Asthma Report. Auckland.

[49] Samoli, E., et al. (2011) Acute Effects of Air Pollution on Pediatric Asthma Exacerbation: Evidence of Association and Effect Modification. Environmental Research, 111, 418-424. https://doi.org/10.1016/j.envres.2011.01.014

[50] Penard-Morand, C., et al. (2010) Long-Term Exposure to Close-Proximity Air Pollution and Asthma and Allergies in Urban Children. European Respiratory Journal, 36, 33-40. https://doi.org/10.1183/09031936.00116109 